\title{
InfoNorth
}

\section{A Multiscale Study of Tree-Line Dynamics in Southwestern Yukon}

\author{
by Ryan Danby
}

\section{INTRODUCTION}

A CONSISTENT PREDICTION OF GLOBAL CHANGE RESEARCH is that climate warming will be greatest in Arctic and Subarctic regions, and recent trends certainly support these predictions. The potential ecological impacts of such change have been the subject of numerous studies, and one of the more common hypotheses is that the transition between forest and tundra zonesgenerally referred to as the tree line-will undergo a significant change as a result. Several studies have already observed changes at the latitudinal tree line in northern Canada, Alaska, and Russia in response to warming over the past 150 years, and analogous changes have been observed in many mountainous regions around the globe. However, these changes have not been uniform in type and extent. In some regions, trees have invaded tundra, extending the altitudinal or latitudinal limit of tree growth. In other regions, the tree component has not changed, but an increase in the number and size of woody shrubs has been documented. In still other regions, no change has been observed at all. The pattern of how and when these changes occurred also varies considerably between locations. It seems, then, that the process of tree-line change is not as general as one might initially anticipate and that responses to climatic change are mediated by environmental conditions at smaller, more local scales.

The overall aim of my research project is to shed light on how the forest-tundra ecotone in the mountainous Kluane region of southwest Yukon will respond to continued climatic change. Here the tree line is largely an alpine phenomenon. Valley forests in the region are dominated by white spruce (Picea glauca). With increasing altitude these forests begin to thin, and by $1200 \mathrm{~m}$, individual trees are markedly shorter. By $1300 \mathrm{~m}$, the spruce component of the vegetation is grouped into thick, low sprawling clumps (often with multiple stems) known as "krummholz" and interspersed with willow (Salix sp.) and birch (Betula glandulosa) shrubs. Only the occasional spruce remains at $1400 \mathrm{~m}$. Although willow and birch shrubs are found at this elevation, tundra vegetation is equally important, and it dominates at higher elevations.

This zone of transition that constitutes the tree line in the southwest Yukon plays a critical role in landscape structure and wildlife habitat, marking the lower and upper limits of many species' distributions and acting as important habitat for other species in its own right. Thus, changes in the location or pattern of the tree line could have important consequences for biodiversity and its conservation in the Kluane National Park and Reserve and the adjacent Kluane Wildlife Sanctuary, as well as for subsistence and other human use of these biological resources. Predicting the impact of climate change on the tree line in southwest Yukon is therefore important for developing planning and management strategies that could help resource managers and local residents adapt to or cope with this change. But such predictions are only as good as the understanding they are built on. This means that to attain an accurate forecast, we need to know (1) how the tree line has responded to climatic change and variability in the past and (2) what factors limit tree growth at high elevations in the region and therefore control tree-line dynamics. The study I have designed to investigate these two questions comprises four linked components, each operating at a particular scale and focusing on a particular element of tree-line dynamics.

\section{PROJECT COMPONENTS}

The period of seedling growth is critical for trees at the tree line, since younger individuals are more susceptible to the damaging effects of extremely cold temperatures. Continued climate warming could cause a change in the position and structure of the tree line by allowing seedlings to surpass this crucial period with fewer adverse effects. To test this hypothesis, I have constructed 40 open-top greenhouses, each containing a single spruce seedling, at elevations between approximately 1250 and $1350 \mathrm{~m}$. My monitoring data show that these greenhouses increase daytime temperature by $3^{\circ}$ to $7^{\circ} \mathrm{C}$ over that of unwarmed seedlings and extend the growing season by up to two weeks. To quantify seedling response to this warming, I am measuring annual increments of vertical, lateral, and radial growth, and in 2004, I will measure differences in rates of photosynthesis and respiration. Results from the first complete year of warming did not indicate any treatment response, likely because greenhouses were erected 


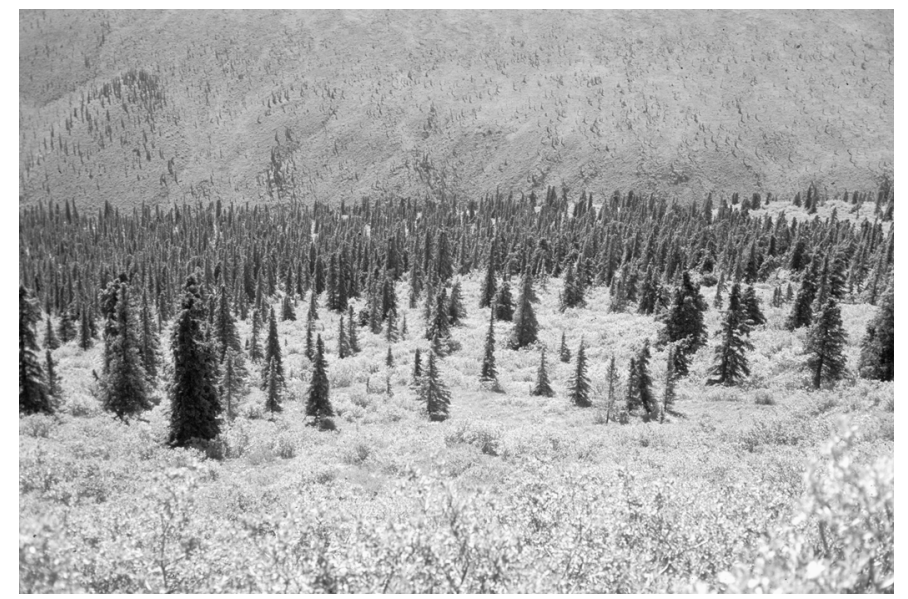

An example of the tree line in the Kluane Ranges.

after bud formation the previous year. However, I anticipate that data from the second and third years of the experiment will indicate a difference between warmed and unwarmed seedlings that can be attributed to temperature change.

The second component of my project uses dendrochronology, or tree ring analysis, to identify periods and rates of spruce and willow establishment and relates these events to past climatic change. The working hypothesis is that both tree and shrub components have responded to past climatic warming by increasing recruitment, resulting in a tree line that is higher or denser (or both), but that this response differs depending on the influence of topography. Sampling was carried out during the summer of 2002 to obtain wood cores and sections from 18 plots located in the Kluane Ranges northwest of Burwash Landing. Spruce and willow trees in each plot were measured (height and diameter) and then either sectioned or cored. In total, more than 750 spruce and 900 willows were sampled. The annual rings in each sample are being counted in order to age each tree. Tree ages will then be tallied to yield a population age distribution for each plot. Periods of establishment and mortality can then be compared to regional climate records to assess the relative importance of various climatic variables in tree growth, as well as the process by which the tree line has responded to climatic fluctuations in the past.

In contrast to the dendrochronological investigation, which emphasizes the process of change, the third investigation is intended to identify changes in the pattern of land cover-specifically tree cover-that have occurred at the forest-tundra ecotone. The earliest aerial photographs available from the region (1947) are being compared with the most recent corresponding photographs (1989) for several locations in the northern portion of the Kluane Ranges. Changes in the upper limit of tree growth, as well as in the density of tree cover, are being identified using a combination of digital techniques and stereoscopic viewing of the original photographic prints. Inspection of the photographs to date indicates that instances of upward

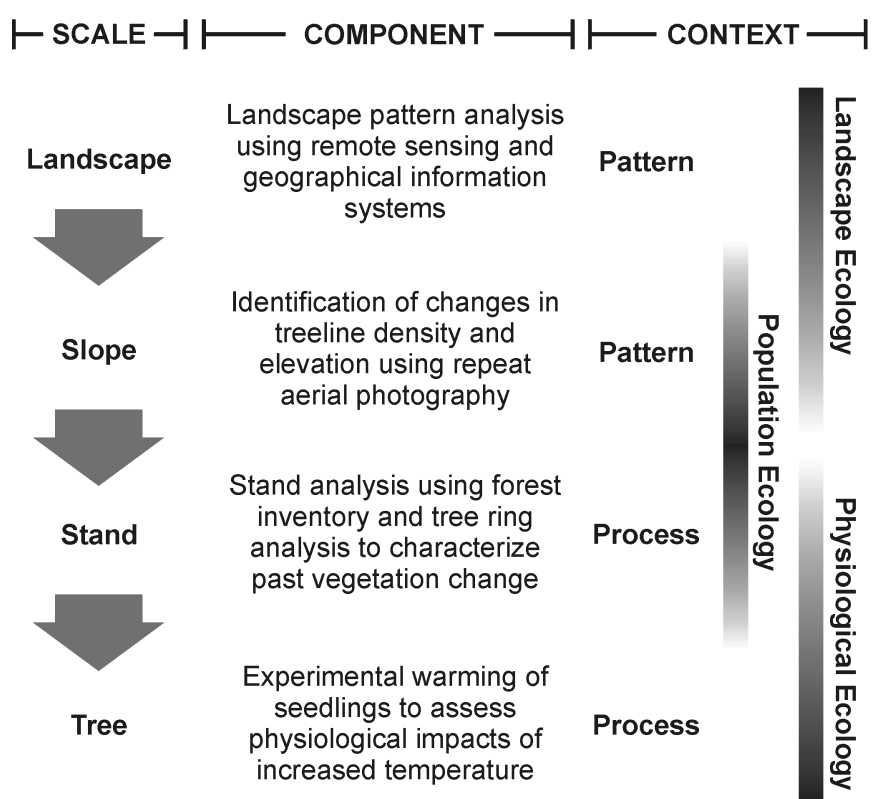

The multiscale framework used in this study.

movement of the tree line are most evident at valley heads. Changes along mountain slopes are more subtle and appear to be associated mainly with increases in tree density in the forest and woodland subzones.

The fourth component of this multiscale study uses spatial information technology to examine how the elevation, density, and relative abruptness of the tree line are related to broad-scale geophysical and topographic variables. First, land cover at the forest-tundra ecotone is being mapped using a technique that combines analysis of multispectral (Landsat) and hyperspectral (Hyperion) satellite imagery, as well as extensive field reconnaissance. Following image classification, the spatial pattern of the

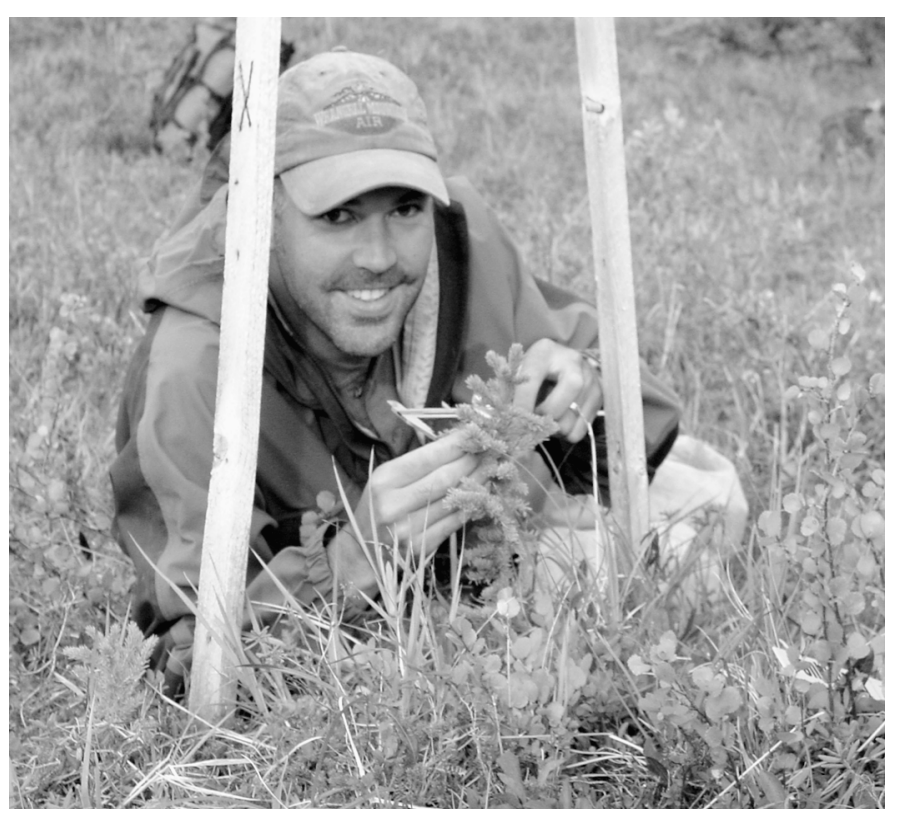

Ryan Danby measuring spruce seedlings. 


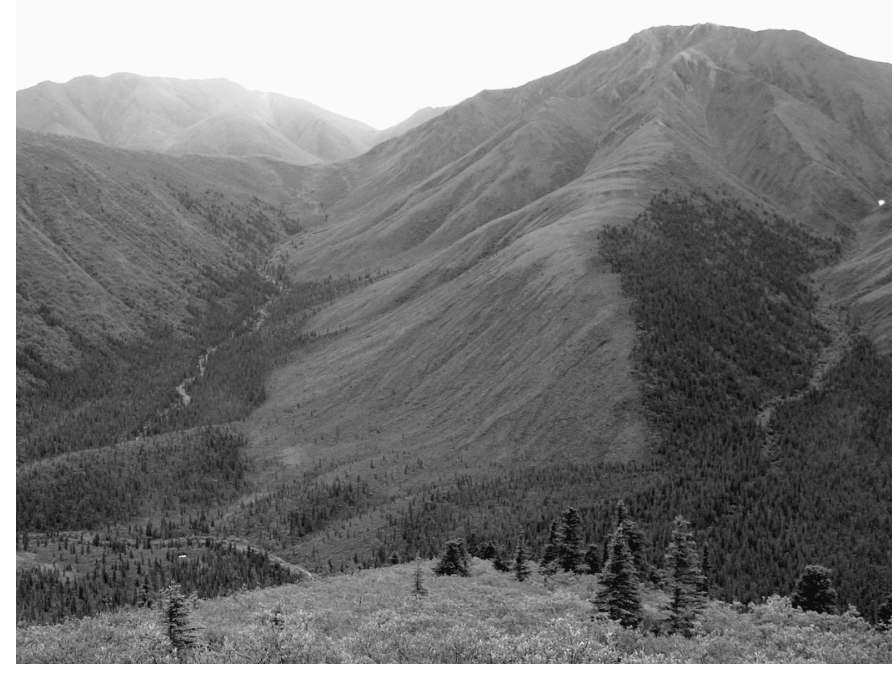

The influence of topography on tree-line pattern.

ecotone is characterized using a geographical information system (GIS). A set of topoclimatic indices, including slope, aspect, and solar irradiance, has been modelled for the study area, and a suite of statistical techniques will be used to explore and quantify the relationships between these indices and the elevation, vegetation composition, and land cover pattern of the tree-line ecotone. Analysis carried out to date indicates that aspect plays a very strong role in controlling landscape-scale variations in tree-line elevation. On average, the tree line is more than $100 \mathrm{~m}$ higher on south aspects than on north aspects because these more exposed slopes receive more sunlight.

\section{SIGNIFICANCE}

The methods of all four project components have been used to study vegetation dynamics elsewhere, and many have been tested successfully in tree-line environments. However, their integration and application to a single region makes this study unique, and the results will yield new knowledge useful in determining how northern mountain ecosystems respond to climatic change. From a regional perspective, the data collected and relationships derived from each investigation could be used in modeling future landscape change in the southwest Yukon. In turn, such a model could be used to facilitate a prediction of how subalpine habitat change could affect land cover and wildlife habitat across the Kluane region.

\section{ACKNOWLEDGEMENTS}

I am truly honoured to be the recipient of the Arctic Institute of North America's Jennifer Robinson Memorial Scholarship. Funding for this research has also been provided by the University of Alberta (Ph.D. Scholarship, Province of Alberta Graduate Fellowship), the University of Alberta Canadian Circumpolar Institute (Circumpolar/ Boreal Alberta Research Grant), Steve and Elaine Antoniuk (Graduate Scholarship in Northern Research), and the Canadian Department of Indian Affairs and Northern Development (Northern Scientific Training Program). Additional funding has been provided through an NSERC Discovery Grant and Canadian Foundation for Innovation grant to D.S. Hik. In-kind contributions from Parks Canada (Kluane National Park and Reserve) and the Yukon Territorial Government (Department of Environment) are also greatly appreciated, as is permission of the Kluane First Nation to carry out research within their traditional territory.

Additional thanks are extended to my supervisor, Dr. David Hik, for all of his help, enthusiasm, and encouragement, as well as to the numerous field assistants who have helped with field work in the Yukon. Finally, I would like to take this opportunity to thank Andy Williams and other AINA staff at the Kluane Lake Research Station for all of their logistical support_and friendship_over the past three years.

Ryan Danby is the recipient of the Jennifer Robinson Memorial Scholarship for 2003. He is currently a doctoral student in the Department of Biological Sciences, University of Alberta. 